\title{
Needle Fear among Children during Mass Measles Rubella (MR) Injectable Vaccination Campaign in North India: an Observational Study
}

\author{
Manvi Singh $^{1} \cdot$ Bhavneet Bharti $^{1}$ (D) $\cdot$ Sahul Bharti ${ }^{2} \cdot$ Shivani Gupta $^{3}$ \\ Accepted: 12 April 2021 / Published online: 24 April 2021 \\ (C) The Author(s), under exclusive licence to Springer Nature Switzerland AG 2021
}

\begin{abstract}
The cross-sectional observational study evaluated the prevalence and predictors of needle-fear among school-going children during mass Measles-Rubella (MR) immunization campaign (year 2017) in the north Indian city of Chandigarh. Fear of needle was assessed using a single-item self-report global question, anxiety was assessed using the Likert scale (score 1-5) and the standardized "Children Faces Scale" where facial responses were graded from 0 to 4. Out of a total sample of 2568 school children, 1225 (47.7\%) reported needle fear (95\% CI: 45.8\%-49.6\%) on a global single item assessment. On an anxiety related Likert scale, $52.3 \%$ did not respond (mainly younger children) and among those who responded, $42.6 \%(523 / 1226)$ showed significant anxiety (score of $\geq 3$ on Likert scale of 1 to 5). Finally, $17.4 \%$ children (95\% CI: $15.9 \%-18.9 \%)(n=446 / 2568)$ scored 2 or above (indicating significant needle fear) on the 'Children Faces Scale' during the actual vaccination procedure. The needle fear were significantly increased among girl students as compared to boys (adjusted OR 2.58; 95\% CI: $2.05-3.24, p<0.001$ ) as well as children accompanied by their parents (adjusted OR 2.05; 95\% CI:1.57-2.69, p < 0.001). On the other hand, needle fear was significantly lowered in children studying in private schools as compared to public school children (adjusted OR 0.45 ; $95 \%$ CI: $0.28-0.74, p=0.002$ ). The needle fear, which was an overriding concern in the minds of girls, children accompanied by their parents, and public-school students, must be proactively addressed for successful mass vaccination campaigns. These findings assume further importance with recent international roll out of COVID 19 vaccine.
\end{abstract}

Keywords Needle fear $\cdot$ Immunization $\cdot$ Campaign $\cdot$ Measles $\cdot$ Rubella $\cdot$ Vaccine

\section{Introduction}

Immunization of children is a frontline strategy for lowering morbidity as well mortality from common infectious illnesses all over the world (Hardt et al., 2016). High vaccination coverage has further assumed paramount importance given the Sustainable Development Goal's target 3 to end preventable

Bhavneet Bharti

bhavneetsahul@gmail.com

1 Social Pediatrics Unit, Department of Pediatrics, Advanced Pediatric Center, Postgraduate Institute of Medical Education \& Research (PGIMER), Chandigarh 160012, India

2 Build Healthy India Movement (BHIM), Chandigarh, India

3 Surveillance Medical Unit Office, World Health Organization, Panchkula, Haryana, India deaths of children by the year 2030. Unfortunately, coverage rates in routinely provided immunization lag behind the desired targets and yield suboptimal benefits in most low middle-income countries (LMICs). To fulfill this wide chasm and meet the deadlines for eradication of preventable diseases, mass vaccination campaigns at the national level are becoming unavoidable (Hardt et al., 2016). The government of India recently launched a mass vaccination campaign against measles and rubella (in short-MR campaign) targeting a total of 410 million school children across the country in a phased manner over a period of 2-3 years (WHO, 2017). This campaign has been considered to be a milestone towards reducing the burden of measles mortality and reducing disabilities due to (CRS) congenital rubella syndrome. Vaccination during the MR campaign was provided through schools and outreach session sites. Such school-based mass vaccination campaigns are, however, underpinned by many organizational and behavioral factors influencing the delivery of vaccines (Perman 
et al., 2017). Three common bottle-necks often highlighted in achieving higher coverage rates for school-based delivery of immunization include- fear or anxiety, informed consent and privacy restrictions (Braunack-Mayer et al., 2015; Taddio et al., 2012). There are already reports regarding the fear of adverse effects (from minor to serious) leading to noncompliance with vaccination among children (Taddio et al., 2012). However, studies regarding fear of needles or injections during mass immunization coverage and its predictors are lacking in developing countries like India. Therefore, we investigated the prevalence as well as predictors of needle fear among school children from North India during a recently conducted school-based MR mass vaccination campaign. The insights gleaned from our study can help plan the inevitable mass vaccination campaigns against the SARS CoV2 virus, to reduce the psychological impact of these activities on children, and on the population as a whole.

\section{Materials and Methods}

This was a cross-sectional observational study conducted during the months of August and September 2017 in the north Indian city of Chandigarh. Children undergoing immunization under the MR campaign in the age group of 4-15 years were enrolled from the public and private schools. As this study was a part of the national campaign for essential MR vaccination, only institutional assent from schools was taken and no separate individual consent was taken from children or caregivers for enrollment in this observational study. An institutional ethical committee approval was taken.

Sample size of the study was based on the previously published estimate of $50 \%$ prevalence rate of needle phobia with 2 -sided confidence interval width of $4 \%$ (i.e. precision $\pm 2 \%$ ) and a confidence level of $95 \%$. A sample size of 2398 was computed, and a final sample size of 2568 children was included.

It was optional for the parents to accompany their child for immunization. Each child's information was recorded on a predesigned proforma which included age, class, whether accompanied by parents or not and adverse events if any. Children were initially asked a single-item self-report global question "Are you scared/ fearful of needles or not?"(binary yes/no response). Also, children's anxiety for the injection was then graded on the Likert scale from 1 to 5, where children were asked to rate the severity of their anxiety for the injection (score 1 and 5 reflected no and severe anxiety respectively).

Under strict aseptic precautions, a trained Auxiliary Nurse Midwife thereafter administered the MR vaccine. The fear of needles wasfurther objectively evaluated in real time during the procedure of vaccination in our study cohort using standardized "Children Faces Scale" (CFS; McMurtry et al., 2011; adapted from a validated Faces Anxiety scale (McMurtry et al., 2011; McKinley et al., 2003). Their facial responses were graded from 0 to 4 . A score greater than or equal to 2 was taken as an indicator of significant needle fear. Children were then observed for side effects for the next $1 \mathrm{~h}$ after immunization. Data collected were entered and processed using Stata 14 (IC version) and R Studio software.

\section{Results}

Out of a total sample of 2568 school children, 1225 (47.7\%) reported needle fear (95\% CI: $45.8 \%-49.6 \%$ ) on the global single-item self-rating assessment with binary response (yes/ no). On anxiety related Likert scale, $52.3 \%$ did not respond (mainly younger children) and among those who responded, $42.6 \%$ (523/1226) showed significant anxiety (score of $\geq 3$ on Likert scale of 1 to 5). Finally, $17.4 \%$ (95\% CI: $15.9 \%$ $18.9 \%)(n=446 / 2568)$ children scored 2 or above on 'Children Faces Scale' during the actual vaccination procedure, indicating significant needle fear (Fig. 1).

The baseline characteristics of the enrolled children are given in Table 1. Notably, there were only two fainting episodes observed in the adolescent age group, which resolved without major intervention. When stratified by the type of school, public school children had a needle fear prevalence of $54.1 \%$ which was significantly higher than the prevalence in children from private schools $(43.8 \%)(P$ value $<0.001)$. It should be noted that in India, the public-school population represents children from a relatively lower socio-economic stratum compared to the private schools. Fifty-two percent of the girl students reported needle fear as compared to only $28.4 \%$ of the boys ( $P$ value $<0.001)$. Needle fear was significantly higher among children accompanied by parents ( $50.1 \%$ vs. $43.9 \%$; P value 0.001$)$. While more children expressed needle fear in parental presence, none of the inoculations were deferred because of the expressed fear.

Also, the highest prevalence of needle fear was in the Nursery/Kindergarten students (52.4\%) and lowest in secondary class students $(40.8 \%)$. For every 5 years increase in educational exposure, the odds of needle fear decreased by $18 \%$ (OR 0.82; 95\% CI: 0.74-0.91; $P$ value $<0.001$ ).

Univariate and multivariate regression analysis was carried out to find out the predictors of needle fear. The results are tabulated in Table 2 . The odds of needle fear were significantly increased among girl students as compared to boys (adjusted OR 2.58; 95\% CI: 2.05-3.24, $p<0.001)$. Interestingly, odds of needle fear were reduced by $55 \%$ among children studying in private schools as compared to government school children (adjusted OR 0.45; 95\% CI: 0.28-0.74, $p=0.002$ ). Finally, students in higher classes showed lower odds of needle fear when compared with children studying in nursery/ 
Fig. 1 Proportion of responses on Children Faces Scale (CFS;

McMurtry et al., 2011) during the immunization in the study cohort

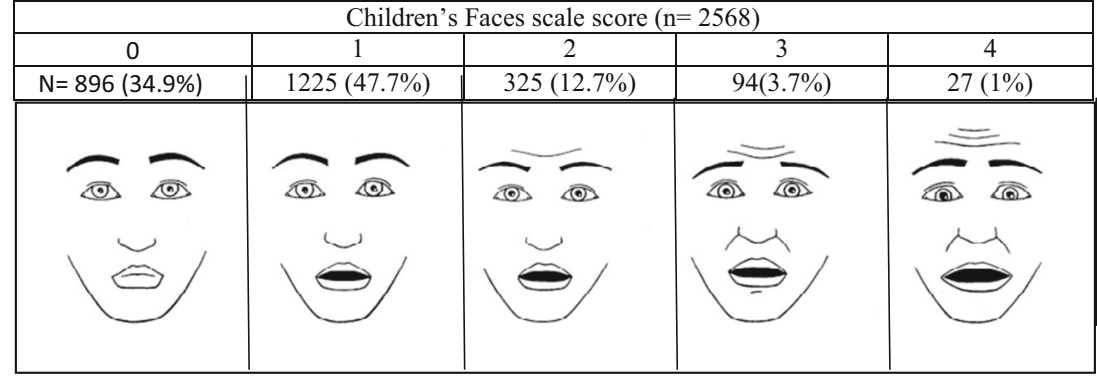

kindergarten classes (Table 2). These results are further highlighted graphically in the forest plot (Fig. 2).

\section{Discussion}

Needle fear is an under-addressed entity that can play an undesirable role by increasing avoidance behavior, particularly

\begin{tabular}{|c|c|c|}
\hline \multirow{3}{*}{$\begin{array}{l}\text { Table } 1 \text { Baseline } \\
\text { characteristics and } \\
\text { prevalence of needle fear } \\
\text { among school children } \\
\text { during MR vaccination }\end{array}$} & Variable & $\mathrm{N}$ (Percentage) \\
\hline & Gender & \\
\hline & Boys & $1215(47.3 \%)$ \\
\hline & Girls & $1353(52.7 \%)$ \\
\hline & \multicolumn{2}{|l|}{ Type of school } \\
\hline & Public & $968(37.7 \%)$ \\
\hline & Private & $1600(62.3 \%)$ \\
\hline & \multicolumn{2}{|l|}{ Education Group } \\
\hline & Nursary/Kindergarten & $531(20.7 \%)$ \\
\hline & Primary & $990(38.5 \%)$ \\
\hline & Middle & $500(19.5 \%)$ \\
\hline & Secondary & $547(21.3 \%)$ \\
\hline & \multicolumn{2}{|c|}{ Parents accompanying their child } \\
\hline & Yes & $1576(61.4 \%)$ \\
\hline & No & $952(38.6 \%)$ \\
\hline & \multicolumn{2}{|c|}{ Needle fear (single global item) } \\
\hline & Yes & $1225(47.7 \%)$ \\
\hline & No & $1343(52.3 \%)$ \\
\hline & \multicolumn{2}{|c|}{ Anxiety Likert Scale score } \\
\hline & 1 (Not at all) & $209(17 \%)$ \\
\hline & 2 (Little bit) & $494(40.3 \%)$ \\
\hline & 3 (Somewhat) & $268(21.9 \%)$ \\
\hline & 4 (Quite a lot) & $168(13.7 \%)$ \\
\hline & 5 (Very much) & $87(7.1 \%)$ \\
\hline & \multicolumn{2}{|l|}{ Children Faces Scale } \\
\hline & 0 & $896(34.9 \%)$ \\
\hline & 1 & $1225(47.7 \%)$ \\
\hline & 2 & $325(12.7 \%)$ \\
\hline & 3 & $94(3.7 \%)$ \\
\hline & 4 & $27(1.0 \%)$ \\
\hline
\end{tabular}

for injectable vaccines. The present study observed that nearly half of the school children (47.7\%) admitted to being afraid of needles. Globally, there appears to be an increasing trend of needle fear in children with reported prevalence of $25 \%$ in 1995 and 63\% in year 2012 respectively (Baxter et al., 2017). More recently, a systematic review and meta-analysis (McLenon \& Rogers, 2019) reported that the majority of children and less than half of the adolescents $(20-50 \%)$ were reported to have a needle fear. Our study prevalence of needle fear was also higher among nursery and kindergarten children (52.4\%) as compared to adolescent children studying in classes 9th and 10th (40.8\%). This finding is consistent with the fact that the peak of needle fear occurs between 5 to 10 years of age among children (McMurtry et al., 2015). The girls in present study were significantly more predisposed to needle fear, a finding that was replicated in the recent meta-analysis as well (McLenon \& Rogers, 2019). Even when adjusted for other confounding variables, the prevalence of needle fear in the present study was 2.58 times higher in girls when compared to boys (adjusted OR 2.58; 95 CI: 2.05-3.24, $p<$ 0.001 ). The possible underlying reasons could be biological as well as the social stereotype, with boys having lesser permission to express fear or cry (Bernstein et al., 1996).

Interestingly, children who were accompanied by parents had a greater prevalence of needle-fear in our study. This presence of the parents may be a prompter enabling children to display their anxiety in an uninhibited fashion. Interestingly, previous research has shown that maternal anxiety is a useful predictor of child anxiety during painful healthcare procedures (Bush et al., 1986; Ollendick et al., 2013; Luthy et al., 2013). Another research by Jay et al. also reported high distress levels among children undergoing painful procedures if their mothers were more anxious (Jay \& Elliott, 1990; Din et al., 2009). On the other hand, pain expression of infants following needle procedures was found to be lower with maternal non-intrusiveness (Din et al., 2009). According to Mahoney et al, the underlying mechanism for childrens' (aged 7-16 years) distress is possibly related to the parents' coping behavior and their response to the stressful environment during injections (Mahoney et al., 2010). Though parental presence emerged as a significant predictor of needle fear in our study, there was a differential effect of parental presence according to the gender of children. $60.5 \%$ 
Table 2 Univariate and multivariate regression analysis for predictors of needle phobia

\begin{tabular}{|c|c|c|c|c|c|}
\hline $\begin{array}{l}\text { Dependent: } \\
\text { Needle phobia }\end{array}$ & & No & Yes & $\begin{array}{l}\text { OR } \\
\text { (univariable) }\end{array}$ & $\begin{array}{l}\text { OR } \\
\text { (multivariable) }\end{array}$ \\
\hline Gender & $\begin{array}{l}\text { Boy } \\
\text { Girl }\end{array}$ & $\begin{array}{l}482(57.3) \\
359(42.7)\end{array}$ & $\begin{array}{l}191(32.9) \\
390(67.1)\end{array}$ & $\begin{array}{c}2.74(2.20-3.42 \\
\mathrm{p}<0.001)\end{array}$ & $\begin{array}{c}2.58(2.05-3.24 \\
p<0.001)\end{array}$ \\
\hline Type of school & $\begin{array}{l}\text { Govt } \\
\text { Private }\end{array}$ & $\begin{array}{l}444(33.1) \\
899(66.9)\end{array}$ & $\begin{array}{l}524(42.8) \\
701(57.2)\end{array}$ & $\begin{array}{c}0.66(0.56-0.78 \\
\mathrm{p}<0.001)\end{array}$ & $\begin{array}{c}0.45(0.28-0.74 \\
p=0.002)\end{array}$ \\
\hline $\begin{array}{l}\text { Parents } \\
\text { accompany- } \\
\text { ing }\end{array}$ & $\begin{array}{l}\text { No } \\
\text { Yes }\end{array}$ & $\begin{array}{l}557(41.5) \\
786(58.5)\end{array}$ & $\begin{array}{l}435(35.5) \\
790(64.5)\end{array}$ & $\begin{array}{c}1.29(1.10-1.51 \\
\mathrm{p}=0.002)\end{array}$ & $\begin{array}{c}2.05(1.57-2.69 \\
\mathrm{p}<0.001)\end{array}$ \\
\hline \multirow[t]{3}{*}{$\begin{array}{l}\text { Education } \\
\text { group }\end{array}$} & $\begin{array}{l}\text { Nursery/KG } \\
\text { Primary }\end{array}$ & $\begin{array}{l}253(18.8) \\
515(38.3)\end{array}$ & $\begin{array}{l}278(22.7) \\
475(38.8)\end{array}$ & $\begin{array}{c}0.84(0.68-1.04 \\
p=0.104)\end{array}$ & $\begin{array}{c}0.85(0.63-1.13 \\
p=0.256)\end{array}$ \\
\hline & Middle & $251(18.7)$ & 249 (20.3) & $\begin{array}{c}0.90(0.71-1.15 \\
p=0.412)\end{array}$ & $\begin{array}{c}0.64(0.43-0.96 \\
p=0.030)\end{array}$ \\
\hline & Secondary & $324(24.1)$ & $223(18.2)$ & $\begin{array}{c}0.63(0.49-0.80 \\
\mathrm{p}<0.001)\end{array}$ & $\begin{array}{c}0.37(0.23-0.58 \\
p<0.001\end{array}$ \\
\hline
\end{tabular}

(288/476) of the girls accompanied by their parents showed fear of needles whereas only $34.1 \%(140 / 411)$ of the boys accompanied by their parents reported a fear of needles. This finding has also been reported by Tsao et al. where parental anxiety had a differential impact, with higher anxiety and sensitivity in girls but not in boys exposed to procedures (Tsao et al., 2006). Our study, therefore, emphasizes the need for strategies to lower parental anxiety and optimize their coping behavior during administration of injectable vaccines to the children.

Fear of needles aggravates reactions like fainting, anxiety, hyperventilation, and lightheadedness. In a campaign setting, a minor and an anticipated event like fainting can trigger mass hysteria which can malign the reputation of the immunization campaign and decrease the compliance of the target population as rumors spread easily and widely (WHO, 2002). Fortunately, in our study, only 2 children were observed to have fainting or vasovagal symptoms which responded quickly to management. The

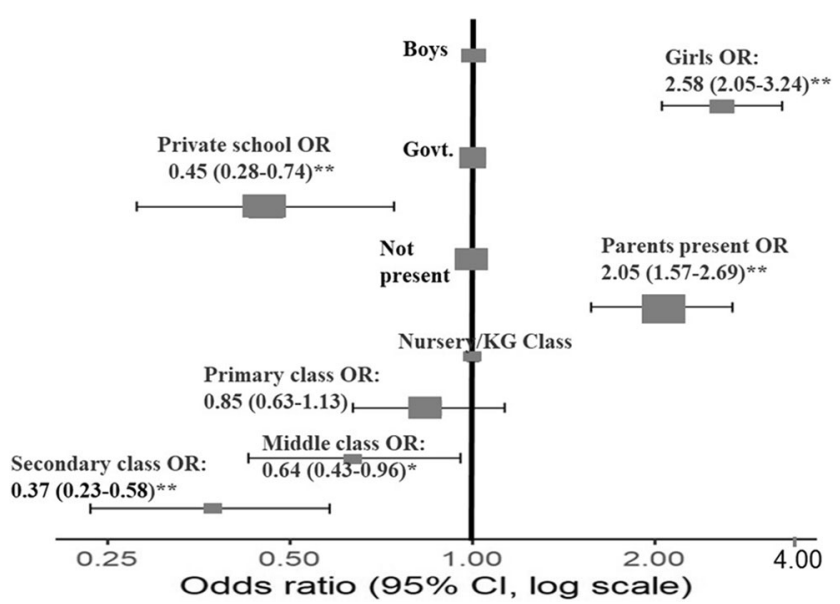

Fig. 2 Forest plot showing multivariate odds ratios for various predictors of needle fear present study also showed a significantly decreasing trend of needle fear with increasing age and years of schooling. This basically signals the limited cognitive capacity of young children studying in nursery or kindergarten classes to appraise the impending stressor,in terms of its intensity as well as duration (Ollendick et al., 2013). Children enrolled in public schools had significantly higher odds of reporting needle fear when compared with private schools. Though we could not find studies examining the association of the type of school and needle fear, this finding may be explained by the poor socioeconomic background of children studying in public schools. Higher childhood anxiety had been linked with the low socioeconomic status of children and it is mediated through higher parental anxiety (Zhu et al., 2019).

The high prevalence of needle fear and its accompanying distress in the pediatric population can be a major driver of vaccine hesitancy, which significantly impedes the health seeking behavior of the population, in the present as well as the future. This needle fear may progress to phobia, if not acknowledged and addressed appropriately. (Orenius et al., 2018; Duff, 2003) As the recent COVID 19 pandemic demands urgent upscaling of vaccination drives, including in children, such strategies need to be incorporated at the level of planning. There is already call for piggybacking childhood vaccination campaign against COVID 19 on the insights available from past measles campaign to empower parental decision making (Klass \& Ratner, 2021). Given the findings of present study, these interventions need to be especially tailored to the more vulnerable younger children, girls and those from the lower socio-economic stratum. Measures like targeted education, use of credible sources of vaccine information and customization of vaccination settings are recommended to lower parental anxiety prior to as well as during vaccination in literature. Limitations of the present study 
include the use of single-item rating scales for needle fear and only one response per student.. However, the use of single-item scales in many diverse outcomes like quality of life, self-esteem, and fear in children had already been validated in the past. Moreover, such scales have the added advantages of practical ease and they are psychometrically robust. Our study did not evaluate needle "phobia" (extreme fear of needle/injection) objectively using the established criteria as defined by ICD \& DSM. Given the observational nature of our study, causal association of predictors with the outcome of needle fear cannot be established. However, the prevalence estimate and effect sizes of association of risk factors with needle fear are robust and generalizable due to large sample size of our study and inclusion of children from all schools of Chandigarh. Finally, our study did not explore how the healthcare providers' communication as well as the children's prior experiences with injections affected their expressed fear and distress.

\section{Conclusion}

The needle fear, in our study, was an overriding concern in the minds of nearly half of the children undergoing immunization, particularly among girls, children studying in nursery \& kindergarten classes, and public-school students. These findings, indeed, underscore the importance of participatory rather than paternalistic approach during any mass injectable vaccine campaign including recent international roll out of COVID 19 vaccine.

Acknowledgements The Authors would like to acknowledge the contribution of Dr. Anu Chopra Dosanjh, District Immunization officer, Chandigarh and the Directorate of Health Services, India for the smooth conduct and organization of the Measles Rubella Campaign in Chandigarh, India.

\section{Declarations}

Conflict of Interests The authors declare that they have no conflict of interest.

\section{References}

Baxter, A. L., Cohen, L. L., Burton, M., Mohammed, A., \& Lawson, M. L. (2017). The number of injected same-day preschool vaccines relates to preadolescent needle fear and HPV uptake. Vaccine, 35(33), 4213-4219.

Bernstein, G., Borchardt, C., \& Perwien, A. (1996). Anxiety disorders in children and adolescents: A review of the past 10 years. Journal of the American Academy of Child and Adolescent Psychiatry, 35(9), 1110-1119.
Braunack-Mayer, A., Skinner, S. R., Collins, J., Tooher, R., Proeve, C., O'Keefe, M., et al. (2015). Ethical Challenges in School-Based Immunization Programs for Adolescents: A Qualitative Study. American Journal of Public Health, 105(7), 1399-1403.

Bush, J. P., Melamed, B. G., Sheras, P. L., \& Greenbaum, P. E. (1986). Mother-child patterns of coping with anticipatory medical stress. Health Psychology, 5(2), 137-157.

Din, L., Pillai Riddell, R., \& Gordner, S. (2009). Brief report: Maternal emotional availability and infant pain-related distress. Journal of Pediatric Psychology, 34(7), 722-726.

Duff, A. J. A. (2003). Incorporating psychological approaches into routine paediatric venepuncture. Archives of Disease in Childhood, 88(10), 931-937. https://doi.org/10.1136/adc.88.10.931.

Hardt, K., Bonanni, P., King, S., Santos, J. I., El-Hodhod, M., Zimet, G. D., et al. (2016). Vaccine strategies: Optimising outcomes. Vaccine, 34(52), 6691-6699.

Introduction of Measles-Rubella vaccine guidelines (campaign and routine immunisation)-National Operational guidelines. (2017). Developed by WHO county office for India for Ministry of Health and Family Welfare, Government of India; Available from: http:// www.searo.who.int/india/topics/measles/measles_rubella_vaccine guidelines.pdf.[Last accessed on 2020 Sep 20].

Jay, S. M., \& Elliott, C. H. (1990). A stress inoculation program for parents whose children are undergoing painful medical procedures. Journal of Consulting and Clinical Psychology, 58(6), 799-804.

Klass, P., \& Ratner, A. J. (2021 Jan 20). Vaccinating children against Covid-19 - the lessons of measles. The New England Journal of Medicine, 384, 589-591. https://doi.org/10.1056/NEJMp2034765.

Luthy, K. E., Beckstrand, R. L., Asay, W., \& Hewett, C. (2013 Dec). Vaccinating parents experience vaccine anxiety too. Journal of the American Association of Nurse Practitioners, 25(12), 667-673.

Mahoney, L., Ayers, S., \& Seddon, P. (2010). The association between parent's and healthcare professional's behavior and children's coping and distress during venepuncture. Journal of Pediatric Psychology, 35(9), 985-995.

McKinley, S., Coote, K., \& Stein-Parbury, J. (2003). Development and testing of a faces scale for the assessment of anxiety in critically ill patients. Journal of Advanced Nursing, 41(1), 73-79.

McLenon, J., \& Rogers, M. A. M. (2019). The fear of needles: A systematic review and meta-analysis. Journal of Advanced Nursing, 75(1), $30-42$.

McMurtry, C. M., Noel, M., Chambers, C. T., \& McGrath, P. J. (2011). Children's fear during procedural pain: Preliminary investigation of the Children's fear scale. Health Psychology, 30(6), 780-788. https://doi.org/10.1037/a0024817.

McMurtry, C. M., Riddell, R. P., Taddio, A., Racine, N., Asmundson, G. J., Noel, M., et al. (2015). Far from "just a poke": Common painful needle procedures and the development of needle fear. The Clinical Journal of Pain, 31(10 Suppl), S3-S11.

Ollendick, T. H., King, N. J., \& Yule, W. (2013). Issues in clinical child psychology- international handbook of phobic and anxiety disorders in children and adolescents. Springer science+ business media LLC.

Orenius, T., LicPsych, Säilä, H., Mikola, K., \& Ristolainen, L. (2018). Fear of injections and needle phobia among children and adolescents: An overview of psychological, behavioral, and contextual factors. SAGE Open Nursing, 4, 2377960818759442 . https://doi. org/10.1177/2377960818759442.

Perman, S., Turner, S., Ramsay, A. I., Baim-Lance, A., Utley, M., \& Fulop, N. J. (2017). School-based vaccination programmes: A systematic review of the evidence on organisation and delivery in high income countries. BMC Public Health, 17(1), 252. https://doi.org/ 10.1186/s12889-017-4168-0.

Taddio, A., Ipp, M., Thivakaran, S., Jamal, A., Parikh, C., Smart, S., Katz, J. (2012). Survey of the prevalence of immunization non- 
compliance due to needle fears in children and adults. Vaccine, 30(32), 4807-4812. https://doi.org/10.1016/j.vaccine.2012.05.011.

Tsao, J. Q. L., Myers, C., Kim, S. N. T., \& Zeltzer, L. (2006). Parent and child anxiety sensitivity: Relationship to children's experimental pain responsivity. The Journal of Pain, 7(5), 319-326.

WHO. (2002). Mass measles immunization campaigns: reporting and investigating adverse events following immunization. 2002 (available at http://www.who.int/vaccine_safety/en/AEFI_measles_ campaigns.pdf (who.int)). Accessed Feb 2021.

WHO. (2017). Introduction of Measles-Rubella vaccine guidelines (campaign and routine immunisation)-National Operational guidelines. Developed by WHO county office for India for Ministry of Health and Family Welfare, Government of India; Available from: http:// www.searo.who.int/india/topics/measles/measles_rubella_vaccine guidelines.pdf. [Last accessed on 2020 Sep 20].

Zhu, Y., Chen, X., Zhao, H., Chen, M., Tian, Y., Liu, C., Han, Z. R., Lin, X., Qiu, J., Xue, G., Shu, H., Qin, S., \& Qin, S. (2019). Socioeconomic status disparities affect children's anxiety and stress-sensitive cortisol awakening response through parental anxiety. Psychoneuroendocrinology, 103, 96-103.

Publisher's Note Springer Nature remains neutral with regard to jurisdictional claims in published maps and institutional affiliations. 